\title{
Bibliometric Analysis of Research in Mathematics Education using Scopus Database
}

\author{
Rafael Julius ${ }^{1 *}$, Muhammad Syawal Abd Halim ${ }^{2}$, Normi Abdul Hadi ${ }^{3}$, Azrul Nizam Alias ${ }^{1}$, \\ Muhammad Hafiz Mohd Khalid ${ }^{1}$, Zulfadli Mahfodz ${ }^{1}$, Fariesha Farha Ramli ${ }^{1}$ \\ ${ }^{1}$ Faculty of Applied Sciences, Universiti Teknologi MARA, Perak Branch, Tapah Campus, 35400 Tapah Road, Perak, MALAYSIA \\ 2 Faculty of Computer and Mathematical Sciences, Universiti Teknologi MARA, Perak Branch, Tapah Campus, 35400 Tapah Road, \\ Perak, MALAYSIA \\ ${ }^{3}$ Faculty of Computer and Mathematical Sciences, Universiti Teknologi MARA, 40450 Shah Alam, Selangor, MALAYSIA
}

Received 29 June 2021 • Accepted 27 October 2021

\begin{abstract}
This study presents a bibliometric analysis of research on mathematics education from 1980 through 2020. The purpose of the study is to provide scientific data on the distribution pattern of mathematics education journals, the most prolific authors, countries, institutions, current research topics, potential international collaboration, and direction of research. A total of 12670 articles were retrieved from the Scopus database and the number of publications is predicted to increase further based on the performance indicator of the cumulative articles. The main topic of interest in the discipline usually centered on problem solving, professional development of teachers, and curriculum, while for mathematics subjects several topics that received the greatest attention included algebra, proof, calculus, technology, geometry, and modeling.
\end{abstract}

Keywords: mathematics education, bibliometric analysis, VOS viewer, scopus database

\section{INTRODUCTION}

Conventional teaching and learning methods have changed as a research education during the last few decades, and mathematics education research is a component of this evolution (Gallagher et al., 2020). Mathematics education, in general, plays a vital role in the development of critical skills that may greatly aid progression towards modernization, such as analytical reasoning and abstraction (Bass \& Ball, 2018; Gravemeijer et al., 2017; Szucs \& Morsanyi, 2014). Recently, there have been some exciting reviews on research in mathematics education, focusing on a current state of progress along with problems, challenges, and potential study courses (Adler et al., 2017; Dreyfus et al., 2018; Engelbrecht et al., 2020; Inglis \& Foster, 2018; Nivens \& Otten, 2017; Schoenfeld, 2016; Yore \& Lerman, 2008).

Although this particular topic of interest has received significant attention in the literature, fundamental questions like what is the essence, hidden research patterns, and course of growth of mathematics education from a bibliometric perspective have remained the topic of scholarly discussions within the educational community. For this reason, there is a need for updated information on mathematics education research using bibliometric data. Compared with systematic review papers, bibliometric research includes a statistical study of published articles to define patterns internationally in specific fields. This implementation makes it possible to analyze data from citation indices to assess the reputation and influence of particular papers, authors, and research publications.

Besides, bibliometric citation analysis enables one to quantitatively evaluate the main journal titles and keywords and stream publications in academic contexts in a more coordinated way. Among other relevant data relating to academic society, interaction among authors from various universities, institutions, and countries can be visualized.

Bibliometric studies have been very prominent in literature for many decades, owing to their contribution

(c) 2021 by the authors; licensee Modestum. This article is an open access article distributed under the terms and conditions of the Creative Commons Attribution License (http://creativecommons.org/licenses/by/4.0/). 


\section{Contribution to the literature}

- This research provides current information on the state of mathematics education research from bibliometric perspectives.

- The information offered here aids us in better comprehending and appreciating the essence, hidden patterns of research, and the direction of mathematical education.

- The study visualizes scholarly networks, communications, and developments to identify future international collaborations and research areas.

to state of the art in making known many areas of interest (Cancino et al., 2017). For instance, particular research phenomena can be assessed and investigated in different fields from social sciences (Aria et al., 2020; Uribe-Toril et al., 2020) to science and technology (Andreo-Martínez et al., 2020; Jiang et al., 2020), engineering (Haleem et al., 2020; Marzi et al., 2020), education (Gil-Doménech et al., 2020; Shen \& Ho, 2020), etc. Recently, Drijvers et al. (2020) have worked deeply on the value of the method of bibliometrics and educational content. In mathematics education research, the method of systematically searching for literature using bibliometric tools in combination with a more qualitative and expert approach based on experience was exciting and challenging. However, bibliometric tools are rarely used in mathematics education research.

Few studies were carried out using bibliometric analysis to chart the global research pattern on mathematics education. For example, in the context of historical mathematics growth (Behrens \& Luksch, 2011; Ersozlu \& Karakus, 2019; Hernández-Torrano \& Ibrayeva, 2020). However, these are more relevant to general mathematics, mathematics anxiety, and creativity in education. Jiménez-Fanjul, Maz-Machado, and Bracho-López (2013) reported a bibliometric study about the mathematics education research in the Social Sciences Citation Index (SSCI) accessing through the core collection database of the Web of Science (WoS). This study discussed the co-authorship patterns, diachronic production, the universities' productivity, and the most important institutional collaboration networks. However, the result is limited to only four mathematics education journals indexed in the SSCI. Subsequently, extended bibliometric analysis concerning research on mathematics education based on the same database has been addressed (Özkaya, 2018). As a repository that hosts bibliographic data, WoS makes important contributions to bibliometric work. Not all mathematics educational journals, however, are covered within the WoS database. Therefore, a comprehensive review of the topic is insufficient. Niven and Otten (2017) reported in recent years that only $8.7 \%$ of the 69 mathematics education journals analyzed for quality assessment in their study appeared in the WoS database. This leads to the conclusion that the WoS database is inadequate for mathematics education (Jiménez-Fanjul et al., 2013; Niven \& Otten, 2017).
A broad range of content, including papers, books, and conference proceedings on a large variety of subjects, can be searched for using another database like Google Scholar. However, the search results are not comprehensive. Since Google Scholar does not allow users to restrict findings to either peer-reviewed or not, results frequently differ in quality, and manual screening is needed to decide which results are acceptable. As the most extensive database for peerreviewed literature, Scopus, on the other hand, includes the primary research journals in mathematics education (Niven \& Otten, 2017). Therefore, it is necessary to select the Scopus database as a primary source for data mining. Most recently, a scientometric look at mathematics education from the Scopus database has been reported with "mathematics education" as the main query string for the search purpose (Ramírez \& Devesa, 2019). It is common that when an author writes specifically for a mathematics education journal, those words would not be included as implied as these terms are self-evident. Some authors might not file their work as a subject under 'mathematics education.' This will limit the search criteria, and many relevant documents will not be found and included in the analysis. A more comprehensive query string should therefore be recommended to be used.

As an actual effort to aid development in mathematics education, this study aims to explore further the global research trend of mathematics education using the Scopus database. The objectives of this review are to provide scientific information on; (i) the publications of mathematics education journals, (ii) the most active authors, countries, and institutions, (iii) the research focus based on the most frequently occurring keywords, and (iv) the analysis on structure and dynamics of connections and network collaborations. These data will be useful in acknowledging and understanding the essence, hidden patterns of research, and the growth course of mathematics education. Furthermore, the data provides a visualization of scholarly networks, communications, and developments for potential international collaborations and research directions. The rest of the paper is organized as follows. After a brief introduction, we present an overview of the bibliometric approach, followed by a theoretical framework in the methodology section. The next section discusses the findings of the 
study. Following that, the final section concludes with a summary.

\section{METHODOLOGY}

This study established global research patterns in mathematics education using bibliometric methods. This technique combines systematic analysis of published articles, including citations, to assess the article's impact (Maditati et al., 2018). To chart the trends on the current subject, several indices such as the distribution of the publication over time, journals, countries, institutions, authors' performances, and the main subjects receiving the most attention and their shifts in foci over time were quantitively analyzed.

\section{Theoretical Framework}

The data mining protocol was created using the Preferred Reporting Items for Systematic Reviews and Meta-Analyses statements and reporting checklist as a guideline (PRISMA; Liberati et al., 2009). This procedure comprises crucial aspects for transparent reporting and bias minimization, resulting in relevant research concepts and credible findings. Furthermore, the search string includes no exclusions for publications written in languages other than English to avoid language bias. We checked the titles, abstracts, and sometimes the complete content of the documents to ensure that the search result was accurate.

The literature obtained in this study was extracted from the Scopus database in January 2021 (https://www.scopus.com/) with the central theme "mathematics education". The following query string: (TITLE-ABS-KEY(mathematics AND (edu* OR teach* OR learn* OR train* OR pedagogy OR student* OR curricul*))) AND DOCTYPE (ar) AND PUBYEAR > 1979 AND PUBYEAR < 2021 AND (LIMIT-TO (SRCTYPE, " $j$ ")) have been applied on the advance search of Scopus and a total of 46798 articles have been collected from 1980 to 2020 .
Application of the query string (TITLE-ABS-KEY) helps the search engine capture articles relevant to the central theme by defining the title, abstract, or keywords. To extend the search criteria, the asterisk $\left(^{*}\right)$ symbol replaces any number of characters. For example, teach* searches for all variants such as teach, teacher, teachers, teacher's teachers', teaching, etc. Furthermore, an analysis of the search output before 1980 revealed that the trend in publication over the years was inconsistent with the small number of articles published annually, especially before the 1970s. This is in line with Schoenfeld et al. (2016) study, where research began to progress in the 1980s in mathematics education, after the New Mathematics Movement in 1960. This serves as the principal reason for selecting the period from 1980 to 2020 for the current analysis. Besides, the chosen period is comparable to a recently published general model based on data extracted from the WoS Core Collection database (Özkaya, 2018).

The search results (46 798 articles) are composed of broad subject areas, and therefore additional filtering is required. Additional phrases were added to the search string to concentrate only on articles substantially relevant to mathematics; AND (LIMIT-TO (SUBJAREA, "MATH"). These documents were analyzed and presented in the form of a graphical plot, tables, and images wherein the most prolific journals, countries, institutions, and authors are identified based on the total number of publications (TP), total citations (TC), CiteScore (CS) and document h-index (h-i). Figure 1 exhibits a flowchart of the collection of data and search strategy.

Information on the intra-national collaboration was obtained based on Single Country Publication (SCP) data implementing a field code AFFILCOUNTRY. On the other hand, the international collaboration network between the selected countries was analyzed using similarity software visualization, i.e., VOS viewer. In particular, VOS viewer is handy for the visualization of a scientific environment as well as other research domains. It allows bibliometric networks such as

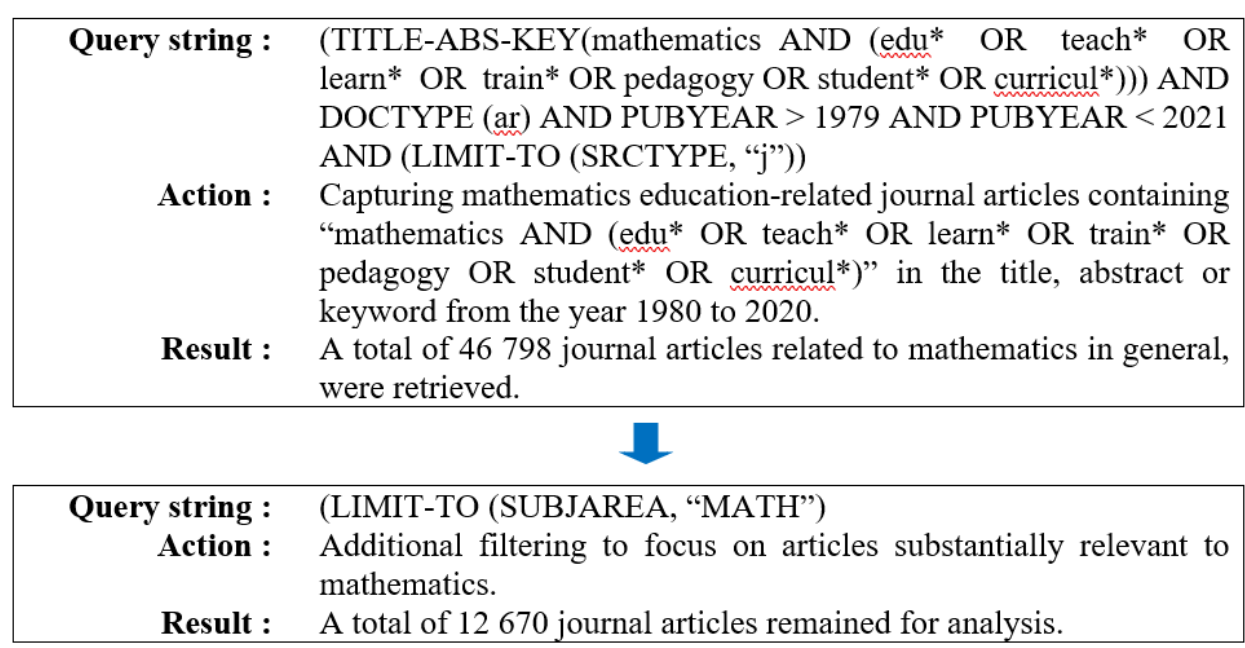

Figure 1. Flowchart of data collection and search strategy 


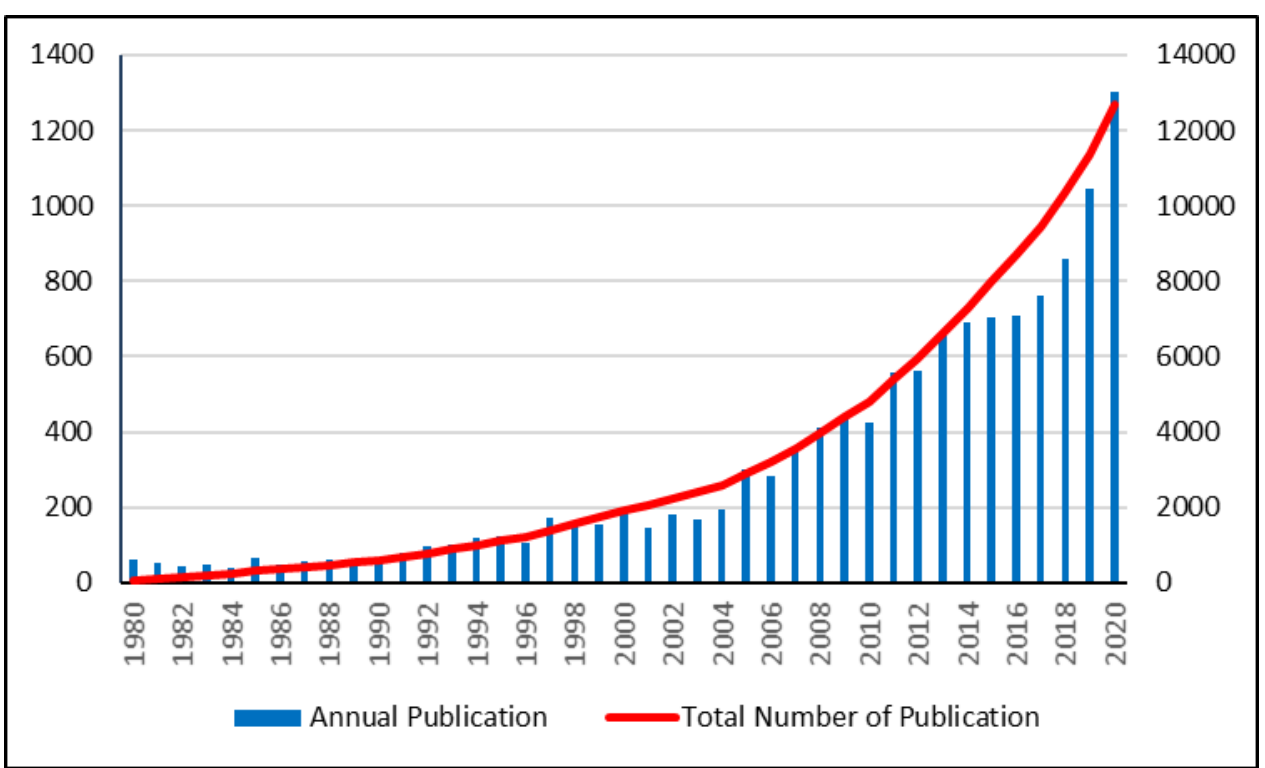

Figure 2. Distribution of the publication on mathematics education studies indexed in Scopus from 1980 to 2020

research authors, journals, institutions, and individual publications to be produced, visualized, and analyzed. In these visualizations, countries are defined by a frame and a link. The size of the frame correlated to the number of papers that have been published by the countries in question, while the size of the link reflects how active countries are in international collaboration. The more active and involved countries are in publishing and coauthoring research papers, the greater countries' frames, and links, and vice versa. Besides, the distance from one frame to another defines the strength of collaboration between countries. In general, a smaller gap implies a better partnership. The analysis was carried out on the author's keywords in a similar way to assess the research interest and changes in the focus of study interest over time, except that the changes in focus were segregated for every five and six years. Notice that certain countries or keywords may not appear on the figures to avoid overlapping marks. Nevertheless, for more comprehensive mapping, we have made these files available online.

\section{RESULT AND DISCUSSION}

\section{Growth Rates}

Figure 2 shows the publication output on mathematics education studies from 1980 to 2020 at a 41year interval. The clustered column shows the publication's annual rise, and the solid line deals with the total number of the publication. The publication output for the first 13 years of the selected period (19801992) can be seen to be relatively low, with less than 100 articles being published annually. A substantial increase in the number of publications is observed to be started in 2005, reflecting the growth of research interest. Additionally, this could also indicate a number of other things like the growth in education and mathematics due to wider publication options, increased active researchers, and increased networks of collaborators. These numbers fluctuate over time. Nevertheless, the cumulative data shows a solid overall growth trend, particularly in the last five years of the $12670 \mathrm{TP}$ interval. Interestingly, despite the global pandemic and worldwide severe economic recession, the year 2020 recorded the highest annual growth rate, with an increase of $19.66 \%$ from the previous year. This could be due to the rise of digital learning, which has been accelerated by the pandemic. Based on that growth trend, the number of annual publications is expected to increase further.

To note, only $27.04 \%$ (3426) of the total publications are accessible for free. Therefore, it is recommended to publish articles in a journal as an open-access type to promote citations. The literature obtained in this study was published mainly in the English language at $93.65 \%$ (11 866 articles), followed by Portuguese at 2.41\% (305 articles) and German at $2.18 \%$ (276 articles). Other languages such as Spanish, Chinese, Turkish, French, Italian, Russian, Korean, Hungarian, Indonesian, and Polish contributed 223 articles to the remaining percentage. The language of publication depends on the journal. However, to be indexed in Scopus, the title and abstract have to be written in English. In addition, the query string used in this study does not contain any restrictions on foreign articles, thus allowing the string to capture all articles, and therefore, authors, institutions, and countries that fall within the categories. The TP covers another 24 mathematics-related topics and the ten most commonly covered areas of mathematics in Social Sciences, Computer Science, Engineering, Psychology, Physics and Astronomy, Decision Science, Art and Humanities, Biochemistry, 
Table 1 . The top 10 most prolific journals based on the number of cumulative publications

\begin{tabular}{|c|c|c|c|c|c|}
\hline & Journal & $\mathrm{TP}(\%)$ & TC & CS The most cited article & TsC Publisher \\
\hline 1 & $\begin{array}{l}\text { International Journal of } \\
\text { Mathematical Education in }\end{array}$ & $\begin{array}{l}1184 \\
(9.34)\end{array}$ & 5230 & $\begin{array}{l}\text { 1.4 Student learning and perceptions in a flipped } \\
\text { linear algebra course }\end{array}$ & 189 Taylor \& Francis \\
\hline
\end{tabular}

Science and Technology

2 ZDM International Journal

$10089894 \quad 3.6$ Fostering creativity through instruction rich in 209 Springer Nature on Mathematics Education (7.95) mathematical problem solving and problem posing

3 Educational Studies in

$97519643 \quad 2.8$ The relationship of teachers' conceptions of Mathematics mathematics and mathematics teaching to instructional practice

4 Primus

5 Mathematics Education Research Journal

6 Journal of Mathematical Behavior

7 International Journal of Science and Mathematics Education

8 Bolema Mathematics Education Bulletin

9 Eurasia Journal of Mathematics Science and Technology Education

10 Teaching Mathematics and its Applications TsC: Times Cited
1388

$0.6 \mathrm{G}$

Gamification and web-based homework

4157 2.5 The transition to formal thinking in mathematics

56321.9 Habits of mind: An organizing principle for mathematics curricula

4128 3.1 How science, technology, engineering and mathematics (STEM) project-based learning (PBL) affects high, middle and low achievers differently: the impact of student factors on achievement

5140.5 Onto-semiotic approach to mathematics teacher's knowledge and competences

26043.0 The impact of motivation on student's academic achievement and learning outcomes in mathematics among secondary school students in Nigeria
12621.7 Using a personal response system for promoting student interaction
288 Springer Nature

72 Taylor \& Francis

104 Springer Nature

152 Elsevier

129 Springer Nature

\section{BOLEMA}

Departamento de Matematica

96 Modestum Ltd.

72 Oxford University Press
Genetics and Molecular Biology, and Environmental Science.

\section{The Most Prolific Journals}

Table 1 showcases the top ten most prolific journals. Notice that the list is arranged within the selected period based on the number of cumulative publications. Among the list were three journals; Educational Studies in Mathematics (ESM), Journal of Mathematical Behavior (JMB), and ZDM International Journal on Mathematics Education (ZDM), which also appeared in Tier 1 list of the most prestigious journals in the field (Nivens \& Otten, 2017). With 1184 publications, the International Journal of Mathematical Education in Science and Technology (IJMEST) was the most prolific, representing $9.34 \%$ of the cumulative amount, closely followed by ZDM (1008 publications, 7.95\%). ZDM is one of the oldest academic journals in the area of mathematics education. These data reflect all the releases of ZDM in Scopus, including its previous version, i.e., ZDM - mathematics education.

Furthermore, ESM and Primus are ranked third- and fourth-place, with total publication 975 (7.69\%) and 717 $(5.66 \%)$. Other most prolific journals are Mathematics Education Research Journal (MERJ) 504 (3.98\%), JMB 465
(3.67\%), International Journal of Science and Mathematics Education (IJMSE) 457 (6.31\%), Bolema Mathematics Education Bulletin (BOLEMA) 397 (3.13\%), Eurasia Journal of Mathematics Science and Technology Education (EJMSTE) 374 (2.95\%), and Teaching Mathematics and its Applications 364 (2.87\%). ESM registered the highest TC (19643), followed by Journal for Research in Mathematics Education (JRME) (13949 TC), ZDM (9894 TC), and JMB (5632 TC). By contrast, BOLEMA owned the lowest CS (0.50). BOLEMA has published articles in three different languages, i.e., English, Spanish, and Portuguese. The abstract of the papers is generally available in English; however, the full texts are hard to find. The abstract alone is not sufficient in most cases, so the number of audiences and citations, particularly from the English reader, may be limited. Furthermore, all of the journals within the list belong to four notable publishers. A total of four journals are owned by Springer Nature, two journals by Taylor \& Francis. In contrast, Elsevier, BOLEMA Departamento de Matematica, Modestum Ltd., and Oxford University Press owned one journal, respectively.

Although the TP index is essential for determining journal selection among authors, it is also recommended to look into the journal's reputation in presenting highquality works to the right audience - the classification 
Table 2. Top 7 most active countries and academic institutions based on the number of cumulative publications on mathematics education study

\begin{tabular}{llcrlll}
\hline \multicolumn{1}{l}{ Country } & TPC & SCP (\%) & $\begin{array}{l}\text { The most active academic } \\
\text { institution in the country }\end{array}$ & $\begin{array}{c}\text { TPI The most active academic institution } \\
\text { worldwide }\end{array}$ \\
\hline 1 & US & 4389 & 83.34 & Michigan State University & 104 University of Witwatersrand \\
2 & UK & 1244 & 70.73 & Loughborough University & 100 Utrecht University & 109 \\
3 & Germany & 819 & 68.98 & Universität Hamburg & 65 Michigan State University \\
4 & Australia & 793 & 72.38 & Monash University & 101 Monash University & 104 \\
5 & China & 586 & 64.33 & East China Normal University & 33 Loughborough University \\
6 & Canada & 497 & 60.36 & Simon Fraser University & 59 Technion & 100 \\
7 & South Africa & 487 & 75.97 & University of Witwatersrand & 109 UNESP-Universidade Estadual Paulista & 88 \\
\hline
\end{tabular}

TPC: Total publication of a given country, SCP: Single country publication, TPI: Total publication of a given academic institution in the country, TPW: Total publication of a given academic institution worldwide

that will contribute to the current subject's progression. For instance, while JRME is regarded to be the highest in Tier 1 on the recent survey by Niven and Otten (2017), in this analysis, JRME recorded only 290 TP and therefore, is not included as one of the top 10 most prolific journals in terms of the TP. Nevertheless, JRME registered the highest CS (4.1) and among its 290 TP, JRME has nine publications with citations over 200 times. In addition to this, one of JRME's publications, viz. Sociomathematical norms, argumentation, and autonomy in mathematics have been listed with 707 citations as the most cited paper.

\section{Contribution of Countries and Institutions}

Table 2 presents mathematics education research results of the top 7 dominant countries and institutions. The United States (US) posted the largest amount of search results reported (4389 articles), leading to approximately $34.64 \%$ of TP. The United Kingdom (UK) is the second most active country with 1244 (9.81\%) TP followed by Germany (819, 6.46\%), Australia (793,
$6.26 \%)$, China $(586,4.63 \%)$, Canada $(497,3.92 \%)$, and South Africa $(487,3.84 \%)$.

Research on the SCP showed that all countries on the list have a solid intra-country collaborative research network led by the US and South Africa, with $83.34 \%$ and $75.97 \%$ SCP, respectively. Canada reports the least SCP, with $39.64 \%$ of their TP being affiliated with other nations. While South Africa is ranked seventh on the list, the University of Witwatersrand has published the most articles with $109 \mathrm{TP}$ in terms of the number of institutions' publications. In contrast, Michigan State University (US) and Utrecht University (the Netherlands, $205 \mathrm{TP}$ ) recorded $104 \mathrm{TP}$. These results might be related to the number of institutions in the country. For example, South Africa's number of public universities is considerably lower compared to other countries. Therefore, certain institutions may produce more publications if their expertise in the countries is less spread out.

Figure 3 illustrates the bibliometric map of international collaboration between the selected

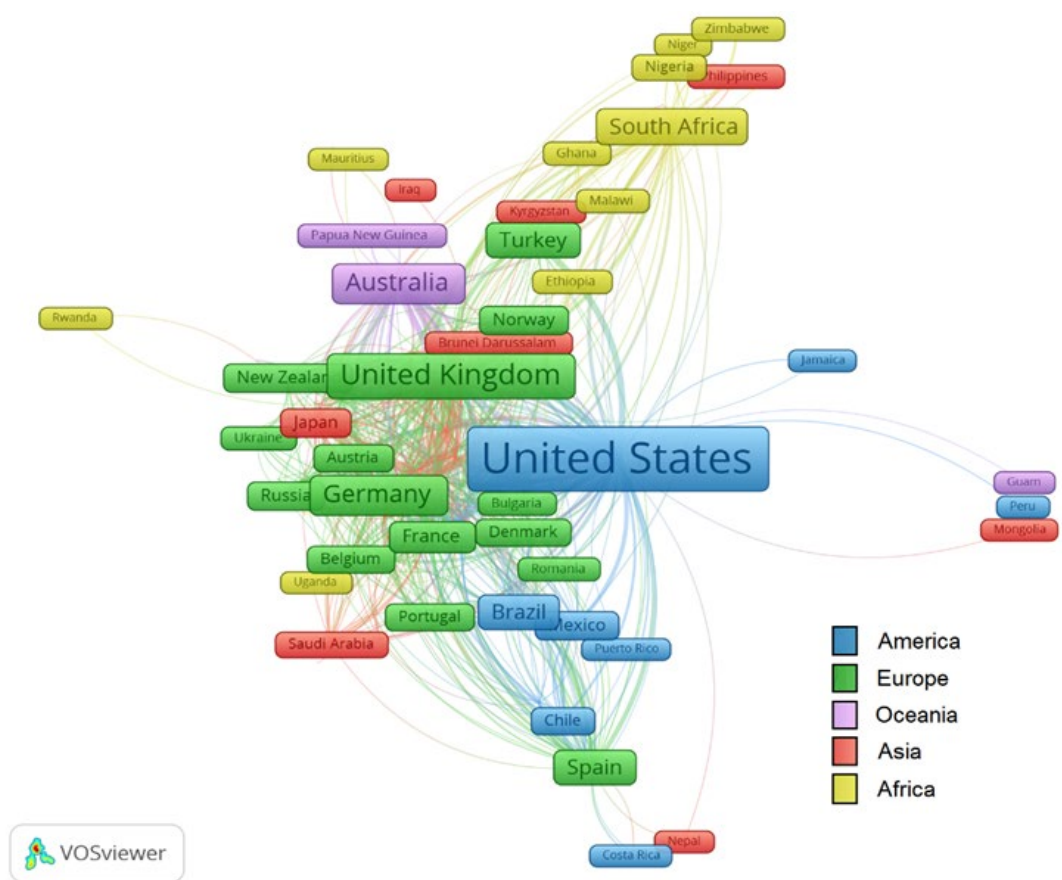

Figure 3. Bibliometric map of international collaboration between the selected countries. For a more detailed mapping, this figure can be open in VOS viewer via: http:/ / bit.ly/2LsIiXJ 
countries with at least five publications using VOS viewer network visualization mode, clustered per region. In this mode, it is possible to determine the degree of co-authorship between countries by looking at how close the countries are and how thick the line connecting them is. Active countries with strong relations tend to be connected with a thicker connecting line and vice versa. The US is the most involved on the international scene, with close ties to another 74 nations. At 84 and 82 total co-authorship, the most vital link connects the US with China and the UK. With 64 links to other countries, the UK is the second most active country for international collaboration. In addition to coauthorship with the US, the UK has close affiliations with Australia (46 co-authorships) and Canada (27 coauthorships). Sharing the top list are Germany (49 links), Australia (45 links), Canada (43 links), South Africa (42 links), Spain (42 links), and China (39 links).

Europe accounted for the highest number of nations per region (38), followed by Asia (35), Africa (34), America (18), and Oceania (5). The UK has shared the highest number of co-authorship papers with Germany (22 co-authorships), becoming the most involved in international collaboration in the European region. Research on mathematics education in the Asian area tends to be based in China, followed by Japan with 39and 37- links, respectively. Within this region, China recorded the most robust collaboration with Hong Kong (39 links). At the same time, Japan, on the other hand, had a limited number of publications with other Asian countries. Instead, it co-authored more papers with European countries and the US. In the African region, research on mathematics education is dominated by South Africa. South Africa is affiliated with 42 other countries. However, only ten collaborating countries are originated from the same region. The other 24 African countries on the map are not linked to South Africa, and based on the current analysis, there are no foreign collaboration networks in some of these countries at all.

In particular, the US is primarily affiliated in the region with Canada (75 co-authorships) among the 18 American nations. There are also records of US collaboration with other countries in the field, such as Mexico (19 co-authorships), Brazil (10 co-authorships), and others. However, the number of papers co-authored with those countries is small. It was also shown that about $98 \%$ of the Oceanian region's TP is originated in Australia. Among the other Oceanian nations, Australia is only affiliated with Papua New Guinea (4 links). Having a well-established international collaboration network has proved beneficial not just for access to new ideas and understanding. However, continuous communication and collaboration may attract students and researchers from across the globe and give new insight for scientific advancement. This opens up opportunities for further growth, especially for countries without collaboration networks such as Tanzania, Morocco, Cote D'Ivoire, Cuba, Libya, Gabon, Sudan, Benin, Jordan, Albania, Malta, and Syria.

\section{The Most Prolific Authors}

Table 3 lists the most prolific authors ranked on the current topic based on their TP with document h-i and TC, respectively. The top search results have drawn 20 authors with more than 20 publications on the subject area. In terms of the TP, the list is led by G. Kaiser from Universität Hamburg Germany, with 44 publications focusing on mathematics related to social sciences, followed by K. Weber from Rutgers University US with 40 TP. Nonetheless, in terms of the TP, S. Blömeke from Universitetet I Oslo Norway is ranked third; however,

Table 3. List of the 20 most prolific authors in mathematics education research

\begin{tabular}{|c|c|c|c|c|c|c|}
\hline & Author & SA ID & $\mathrm{TP}$ & h-i & TC & Current affiliation \\
\hline 1 & Kaiser, Gabriele & 37072762300 & 44 & 15 & 605 & Universität Hamburg \\
\hline 2 & Weber, Keith & 7402658696 & 40 & 12 & 590 & Rutgers University \\
\hline 3 & Blömeke, Sigrid & 13905350300 & 29 & 16 & 482 & Universitetet i Oslo \\
\hline 4 & Goos, Merrilyn & 7005104936 & 28 & 15 & 737 & University of Limerick \\
\hline 5 & Cai, Jinfa & 8972861500 & 28 & 12 & 416 & University of Delaware \\
\hline 6 & Zulkardi, Zulkardi & 57220148251 & 28 & 9 & 264 & Universitas Sriwijaya \\
\hline 7 & Leikin, Roza & 23390058700 & 25 & 12 & 346 & University of Haifa \\
\hline 8 & Sriraman, Bharath & 6506159282 & 27 & 9 & 337 & University of Montana \\
\hline 9 & Prediger, Susanne & 6507014886 & 25 & 8 & 268 & TU Dortmund University \\
\hline 10 & Putri, Ratu I. I & 55874038900 & 25 & 7 & 131 & Universitas Sriwijaya \\
\hline 11 & Williams, Julian & 22936006200 & 25 & 11 & 380 & University of Manchester \\
\hline 12 & Godino, Juan Díaz & 8969497100 & 24 & 11 & 488 & Universidad de Granada \\
\hline 13 & Tabach, Michal & 23478753200 & 24 & 9 & 197 & Tel Aviv University \\
\hline 14 & Engelbrecht, Johann & 55244523100 & 23 & 9 & 276 & Universiteit van Pretoria \\
\hline 15 & Rasmussen, Chris L & 15846899200 & 23 & 10 & 416 & San Diego State University \\
\hline 16 & Verschaffel, Lieven & 6701742239 & 23 & 10 & 445 & Centre for Instructional Psychology and Technology Leuven \\
\hline 17 & Zazkis, Rina & 6602957344 & 23 & 12 & 370 & Simon Fraser University \\
\hline 18 & Drijvers, Paul H.M. & 6506336239 & 22 & 13 & 496 & Utrecht University \\
\hline 19 & Lerman, Stephen & 55411963300 & 21 & 10 & 470 & London South Bank University \\
\hline 20 & Roth, Wolff Michael & 57203214233 & 21 & 8 & 242 & University of Victoria \\
\hline
\end{tabular}

SA: Scopus Author, TP: Total publication, TC: Total citation, h-i: document h-index 


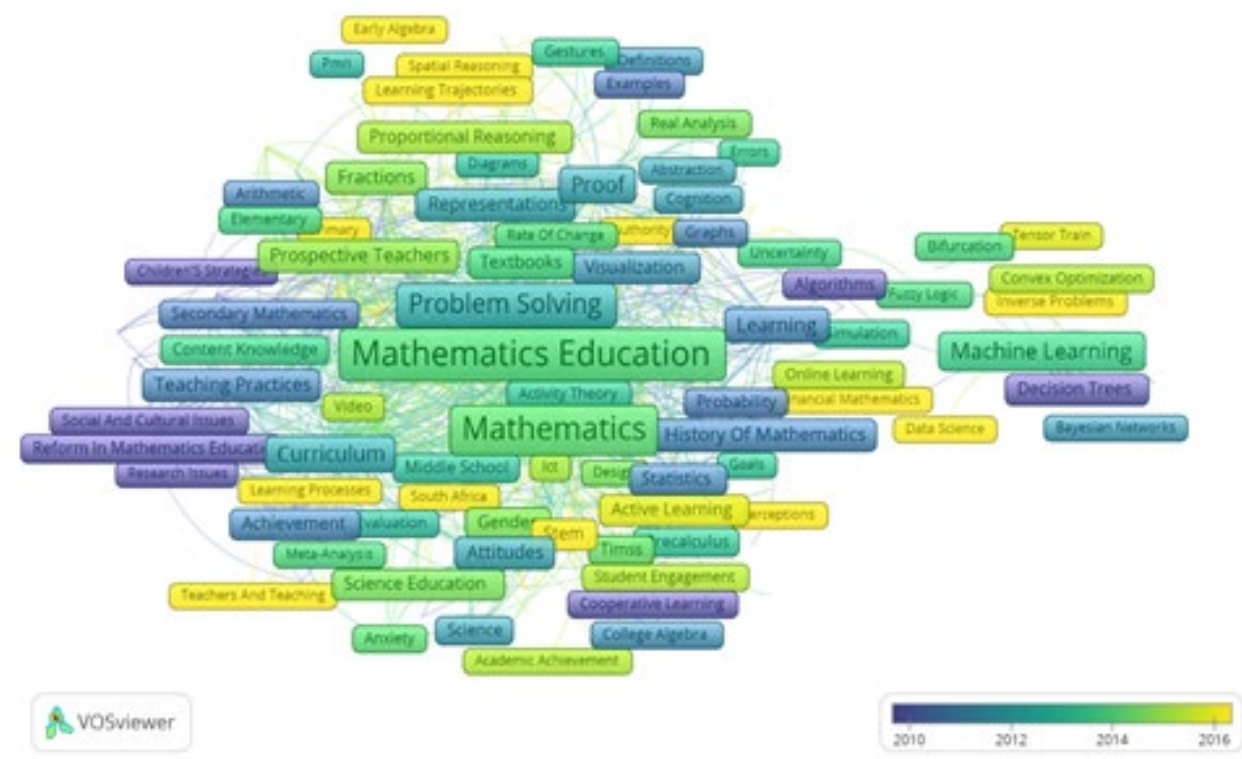

Figure 4. Bibliometric map of author keywords co-occurrence with overlay visualization mode. For a more detailed mapping, this figure can be open in VOS viewer via: http:/ / bit.ly/3sjqHlC

she registered the highest document h-i score (16). Remember that the TP and h-i scores can be used to measure the productivity and impact of the published articles. Nevertheless, the authors should not focus their detailed research output solely on these considerations. For example, in terms of TP, M. E. Goos from the University of Limerick Ireland ranks fourth with document h-i similar to G. Kaiser and lower than S. Blömeke. However, M. E. Goos got her 28 TP with a 737 citation count, the highest TC.

\section{Topic of Interest}

Within this section, we draw attention to the study of the occurrences of keywords to define the research emphasis relating to mathematics education. Of the 22 283 author keywords reported from 12670 articles, 516 keywords meet the threshold of 10 minimum number of keyword occurrences. This number was reduced to 498 keywords in total after relabeling keywords with slight differences using the thesaurus. In Figure 4, the bibliometric map of the keywords is shown using VOS viewer overlay visualization mode to illustrate the effect.

Mathematics education typically offers a perfect foundation for improving problem solving skills. Other than general keywords like 'mathematics education' (629 occurrences, 320 links) and 'mathematics' (521 occurrences, 298 links), the keyword 'problem solving' was the most frequently encountered with 299 occurrences and 232 links to other keywords. Other terms related to problem solving, such as 'problem posing' (39 occurrences, 41 links), 'mathematical problem solving' (23 occurrences, 25 links), 'problem based learning' (13 occurrences, 18 links), and 'problem solving strategies' (11 occurrences, 18 links).
Furthermore, it has been found that there have been numerous research studies conducted on the professional growth of teachers, the context of education, and their connection with student outcomes. As reflected in Figure 4, the keyword 'professional development' was repeated 198 times with 174 links. In comparison, the keywords 'teacher education' and 'teacher knowledge' were repeated 209 times and 141 times each with 177- and 131- co-occurrences. This indicates that teacher performance is often evaluated over the year to quantify the level of development in the field. Among the list, the most frequently used keywords were 'mathematics teacher education' (95 occurrences, 95 links), 'teacher beliefs' (70 occurrences, 78 links), 'mathematics teacher' (63 occurrences, 68 links), and 'teacher learning' (45 occurrences, 57 links).

While most of these studies considered teachers as a subject in general, independent studies between inservice teachers and pre-service teachers are also crucial for more specific detail. The results showed that the keyword 'in-service teacher' was repeated 23 times with 44 total links. On the other hand, keywords containing 'preservice teachers' were repeated 202 times. These included 'preservice teachers' (117 occurrences, 116 links), 'preservice teacher education' (49 occurrences, 68 links), 'preservice mathematics teacher' (25 occurrences, 33 links) and 'preservice' (11 occurrences, 26 links).

The curriculum is another topic that has received substantial attention as it has always been central to teaching and learning in the education system. In this analysis, keywords related to the curriculum were repeated 259 times with 320 links to other keywords. Other than general keywords such as 'curriculum' (141 occurrences, 149 links), 'mathematics curriculum' (51 occurrences, 63 links), and 'integrated curriculum' (11 occurrences, 22 links), other influential attributes 
relevant to the subject include curriculum- development (19 occurrences, 36 links), reformation (14 occurrences, 17 links), design (12 occurrences, 18 links) and implementation (11 occurrences, 15 links).

Further analysis revealed that research on mathematics education within the chosen period has a good establishment of overall educational levels. For the two-stage educational system, the keyword 'primary school' reported 31 occurrences with 44 links. In contrast, the keyword related to secondary school was repeated 53 times with 93 links. These include 'secondary school' (31 occurrences, 58 links) and 'secondary school mathematics' (22 occurrences and 35 links). For the three-stage educational system, keywords 'elementary school' and 'elementary school mathematics' reported 37- and 13- occurrences each with 67- and -16 links, respectively. Compared to the middle school level, research on the high school level has been given more attention (36 occurrences, 53 links). Keywords referring to 'middle school' reported minor occurrences corresponding to 32 occurrences and 45 links.

Furthermore, keywords containing terms reflecting tertiary level education were encountered 306 times with 398 links. The most frequently used keywords were 'undergraduate mathematics' (60 occurrences, 67 links), 'undergraduate mathematics education' (48 occurrences,
53 links), and 'higher education' (42 occurrences, 60 links). At the tertiary level, the most popular topics include (but are not limited to) calculus (181 occurrences, 148 links), active learning (59 occurrences, 60 links), and differential equation (41 occurrences, 53 links). In addition, more than 100 subjects related to mathematics were recognized. Among the subjects, the most frequently used keywords were related to algebra (290 occurrences, 196 links), proof (182 occurrences, 176 links), calculus (181 occurrences, 148 links), technology (144 occurrences, 178 links), geometry (187 occurrences, 232 links) and modeling (262 occurrences, 288 links).

Analysis of the retrieved documents based on the overlaying color range indicated several sub-areas of mathematics education in which there has been a more significant increase in publications over the last few years. Among the most celebrated was the research theme focusing on 'mathematical knowledge for teacher' (75 occurrences, 137 links), 'active learning' (59 occurrences, 104 links), 'inquiry-based learning' (56 occurrences, 94 links) 'geogebra' (47 occurrences, 69 links) and 'statistics education research' (37 occurrences, 38 links).

In Table 4, changes in the focus of study interest over time are given based on the number of occurrences and the link strength overall. However, owing to the limited number of occurrences among the extracted keywords,

Table 4. The shift of Foci in the topic of interest

\begin{tabular}{|c|c|c|c|}
\hline Period & Keywords & Occurrence & Total link strength \\
\hline \multirow[t]{5}{*}{ 1980-1985 } & Compilers & 1 & 2 \\
\hline & Continuous Simulation Languages & 1 & 2 \\
\hline & Interactive Simulation & 1 & 2 \\
\hline & Degenerate Parabolic Equation & 1 & 2 \\
\hline & Stochastic Approximation & 1 & 2 \\
\hline \multirow[t]{5}{*}{ 1986-1990 } & Models & 2 & 11 \\
\hline & Education & 2 & 9 \\
\hline & Logo & 2 & 9 \\
\hline & Teaching & 2 & 8 \\
\hline & Asymptotic Efficiency & 1 & 7 \\
\hline \multirow[t]{5}{*}{ 1991-1995 } & Calculus & 17 & 79 \\
\hline & Mathematics Education & 15 & 50 \\
\hline & Mathematics & 7 & 36 \\
\hline & Algorithms & 4 & 35 \\
\hline & Discrete Mathematics & 4 & 35 \\
\hline \multirow[t]{5}{*}{$1996-2000$} & Reform in mathematics education & 16 & 82 \\
\hline & Problem Solving & 16 & 77 \\
\hline & Calculus & 13 & 56 \\
\hline & Machine Learning & 10 & 56 \\
\hline & Functions & 10 & 52 \\
\hline \multirow[t]{5}{*}{$2001-2005$} & Mathematics Education & 32 & 126 \\
\hline & Problem Solving & 25 & 115 \\
\hline & Proof & 19 & 97 \\
\hline & Reasoning & 12 & 70 \\
\hline & Representations & 10 & 70 \\
\hline \multirow[t]{5}{*}{$2006-2010$} & Mathematics & 82 & 356 \\
\hline & Mathematics Education & 84 & 254 \\
\hline & Problem solving & 45 & 149 \\
\hline & Curriculum & 32 & 138 \\
\hline & Professional Development & 33 & 128 \\
\hline
\end{tabular}


Table 4 (continued). The shift of Foci in the topic of interest

\begin{tabular}{llcc}
\hline Period & Keywords & Occurrence & Total link strength \\
\hline $2011-2015$ & Mathematics Education & 191 & 399 \\
& Mathematics & 143 & 393 \\
& Teacher Education & 80 & 219 \\
& Problem Solving & 87 & 190 \\
& Professional Development & 69 & 174 \\
\hline $2016-2020$ & Mathematics & 263 & 624 \\
& Mathematics Education & 297 & 561 \\
& Problem Solving & 117 & 266 \\
& Teacher Education & 81 & 209 \\
\hline
\end{tabular}

it is difficult to classify the study focus in the first 11 years (1980-1990). The keyword 'mathematics education' is typically more fully attended to than other keywords during the selected period, except for the first 11 years. Mathematics topics such as calculus were a significant concern that attracted considerable attention from 1991 to 1995 . However, the emphasis has increasingly moved to mathematics education in general around 1996 to 2000, where the keyword 'reform in mathematics education' was more encountered. In addition, the emphasis on reforming mathematics education in this era may be attributed to the accelerated growth in interest (number of occurrences) over the next 20 years in these specific subjects. For instance, numerous studies were published after the year 2000 with the keyword 'mathematics education'. Besides 'mathematics' and 'mathematics education' in general, 'problem solving' was another subject that was given much attention from 2000 to 2020. These three keywords have traditionally been the dominant study keywords in the subject for the previous 20 years, except for keywords like 'curriculum' and 'teacher education', which have recently garnered increasing attention. Note that all of the categories included in this analysis were based on the author's keywords alone. Therefore, other information might be missed if the subjects were not listed as keywords on the articles.

\section{LIMITATION OF THE STUDY}

The research topics are extensive and complex since mathematics education studies all concepts and domains relevant to mathematics. In the beginning, the search results yielded a total of 46798 articles. However, such a large number of articles is enormous to be examined in a single study. The search results have been filtered to only include papers directly related to the subject field of mathematics, yielding a total of 12670 articles. For this reason, the data shown here may not include all studies on Scopus linked to mathematics education. The remaining documents may be useful in future studies. Furthermore, within mathematics education research, the rank lists are only intended to provide quantitative insight into the frequency distribution of specified criteria. Therefore, it does not represent the primary way an individual author, university, institution, or country should be assessed for thorough scientific performance and productivity.

\section{CONCLUSION}

Within this analysis, we gave an overview of global research developments within studies of mathematics education. A total of 12670 papers were collected from the Scopus database from 1980 to 2020, and it is expected that the area of mathematics education will continue to develop, based on growth rate success over the last ten years. IJMEST was classified as the most prolific journal, closely followed by ZDM and ESM. Besides, ESM recorded the highest TC number. The US and the UK are the most involved countries publishing through SCP and the international research partnership network led by Michigan State University (US) and Loughborough University (UK). With $109 \mathrm{TP}$, the University of Witwatersrand (South Africa) has written the most papers in terms of global academic institution contribution. Overall, the area of research encompasses all levels of education, and some subjects that have gained the greatest attention include algebra, proof, calculus, technology, geometry, and modeling. Based on the author's keywords review, 'mathematics education' and 'mathematics' are the most commonly used keywords to describe the discipline. A strong emphasis has been put on research relating to the problem solving, professional development of teachers, and curriculum. These five keywords have long been the most popular study terms in the field. Over the last few years, there has been notable growth in publications in numerous sub-areas of mathematics education. The study theme on mathematical knowledge for teachers, active learning, inquiry-based learning, geogebra, and statistics education research were some of the most well-known. The study of mathematics education is expected to grow in the future, particularly concerning the research trend of professional development and problem solving, with more sub-areas and assessment methodologies.

Author contributions: All authors have sufficiently contributed to the study, and agreed with the results and conclusions.

Funding: No funding source is reported for this study.

Declaration of interest: No conflict of interest is declared by authors. 


\section{REFERENCES}

Adler, J., Alshwaikh, J., Essack, R., \& Gcsamba, L. (2017). Mathematics education research in South Africa 2007-2015: Review and reflection. African Journal of Research in Mathematics, Science and Technology Education, 21(1), 1-14. https://doi.org/10.1080/ 18117295.2016.1265858

Andreo-Martínez, P., Ortiz-Martínez, V. M., GarcíaMartínez, N., de los Ríos, A. P., HernándezFernández, F. J., \& Quesada-Medina, J. (2020). Production of biodiesel under supercritical conditions: State of the art and bibliometric analysis. Applied Energy, 264(C), 114753. https:// doi.org/10.1016/j.apenergy.2020.114753

Aria, M., Misuraca, M., \& Spano, M. (2020). Mapping the evolution of social research and data science on 30 years of social indicators research. Social Indicators Research, 149(3), 803-831. https:/ / doi.org/10.1007/ s11205-020-02281-3

Bass, H., \& Ball, D. L. (2018). Review of does mathematical study develop logical thinking? Testing the theory of formal discipline. International Journal of Research in Undergraduate Mathematics Education, 4(3), 442-447. https://doi.org/10.1007/ s40753-018-0076-7

Behrens, H., \& Luksch, P. (2011). Mathematics 18682008: A bibliometric analysis. Scientometrics, 86(1), 179-194. https://doi.org/10.1007/s11192-0100249-x

Cancino, C. A., Merigó, J. M., \& Coronado, F. C. (2017). A bibliometric analysis of leading universities in innovation research. Journal of Innovation $\mathcal{E}$ Knowledge, 2(3), 106-124. https:/ / doi.org/10.1016/ j.jik.2017.03.006

Dreyfus, T., Artigue, M., Potari, D., Prediger, S., Ruthven, K., Artigue, M., Potari, D., Prediger, S., \& Ruthven, K. (2018). Developing research in mathematics education: Twenty years of communication, cooperation and collaboration in Europe. Routledge. https://doi.org/10.4324/ 9781315113562

Drijvers, P., Grauwin, S. \& Trouche, L. (2020). When bibliometrics met mathematics education research: the case of instrumental orchestration. ZDM International Journal on Mathematics Education 52, 1455-1469. https://doi.org/10.1007/s11858-02001169-3

Engelbrecht, J., Llinares, S., \& Borba, M. C. (2020). Transformation of the mathematics classroom with the internet. Transformation of the mathematics classroom with the internet. ZDM - International Journal on Mathematics Education, 52, 825-841. https:/ / doi.org/10.1007/s11858-020-01176-4

Ersozlu, Z., \& Karakus, M. (2018). Mathematics Anxiety: Mapping the Literature by Bibliometric Analysis.
EURASIA Journal of Mathematics, Science and Technology Education 15(2), em1673. https:// doi.org/10.29333/ejmste/102441

Gallagher, M. A., Parsons, S. A., \& Vaughn, M. (2020). Adaptive teaching in mathematics: A review of the literature. Educational Review, 0(0), 1-23. https:/ / doi.org/10.1080/00131911.2020.1722065

Gil-Doménech, D., Berbegal-Mirabent, J., \& Merigó, J. M. (2020). STEM education: A bibliometric overview. In J. C. Ferrer-Comalat, S. Linares-Mustarós, J. M. Merigó, \& J. Kacprzyk (Eds.), Modelling and simulation in management sciences (pp. 193-205). Springer International Publishing. https:/ / doi.org/10.1007/978-3-030-15413-4_15

Gravemeijer, K., Stephan. M., Julie, C., Lin. F-L., \& Ohtani, M. (2017). What mathematics education may prepare students for the society of the future? International Journal of Mathematics and Science Education, 15, 105-123. https://doi.org/10.1007/ s10763-017-9814-6

Haleem, A., Javaid, M., Khan, R. H., \& Suman, R. (2020). $3 \mathrm{D}$ printing applications in bone tissue engineering. Journal of Clinical Orthopaedics and Trauma, 11(Suppl 1), S118-S124. https://doi.org/10.1016/j.jcot.2019. 12.002

Hernández-Torrano, D., \& Ibrayeva, L. (2020). Creativity and education: A bibliometric mapping of the research literature (1975-2019). Thinking Skills and Creativity, 35, 100625. https://doi.org/10.1016/ j.tsc.2019.100625

Inglis, M., \& Foster, C. (2018). Five decades of mathematics education research. Journal for Research in Mathematics Education, 49(4), 462-500. https:// doi.org/10.5951/jresematheduc.49.4.0462

Jiang, D., Shi, B., Ouyang, H., Fan, Y., Wang, Z. L., Chen, Z.-M., \& Li, Z. (2020). A 25-year bibliometric study of implantable energy harvesters and self-powered implantable medical electronics researches. Materials Today Energy, 16, 100386. https:// doi.org/10.1016/j.mtener.2020.100386

Jiménez-Fanjul, N., Maz-Machado, A. \& Bracho-López, R. (2013). Bibliometric analysis of the mathematics education journals in the SSCI. International Journal of Research in Social Sciences 2(3), 26-32.

Liberati, A., Altman, D. G., Tetzlaff, J., Mulrow, C., Gøtzsche, P. C., Ioannidis, J. P. A., Clarke, M., Devereaux, P. J., Kleijnen, J., \& Moher, D. (2009). The PRISMA statement for reporting systematic reviews and meta-analyses of studies that evaluate healthcare interventions: Explanation and elaboration. BMJ, 339, b2700. https://doi.org/ 10.1136/bmj.b2700

Maditati, D. R., Munim, Z. H., \& Schramm, H.-J. (2018). A review of green supply chain management: From bibliometric analysis to a conceptual framework 
and future research directions. Resources, Conservation and Recycling, 139, 150-162. https:/ / doi.org/10.1016/j.resconrec.2018.08.004

Marzi, G., Caputo, A., Garces, E., \& Dabić, M. (2020). A three decade mixed-method bibliometric investigation of the IEEE Transactions on Engineering Management. IEEE Transactions on Engineering Management, 67(1), 4-17. https:// doi.org/10.1109/TEM.2018.2870648

Nivens, R. A., \& Otten, S. (2017). Assessing journal quality in mathematics education. Journal for Research in Mathematics Education, 48(4), 348-368. https://doi.org/10.5951/jresematheduc.48.4.0348

Özkaya, A. (2018). Bibliometric analysis of the studies in the field of mathematics education. Educational Research and Reviews, 13(22), 723-734. https:// doi.org/10.5897/ERR2018.3603

Ramírez, M. C., \& Devesa, R. A. R. (2019). A scientometric look at mathematics education from Scopus database. The Mathematics Enthusiast, 16(4), 37-46.
Schoenfeld, A. H. (2016). Research in mathematics education. Review of Research in Education, 40(1), 497528. https:// doi.org/10.3102/0091732X16658650

Shen, C., \& Ho, J. (2020). Technology-enhanced learning in higher education: A bibliometric analysis with latent semantic approach. Computers in Human Behavior, 104, 106177. https://doi.org/10.1016/ j.chb.2019.106177

Szucs, D., \& Morsanyi, K. (2014). The link between mathematics and logical reasoning: Implications for research and education. In The Routledge international handbook of dyscalculia and mathematical learning difficulties (pp. 101-114).

Uribe-Toril, J., Ruiz-Real, J. L., \& de Pablo Valenciano, J. (2020). The embeddedness of social sciences and economics in research on resources. Resources, 9(2), 15. https:// doi.org/10.3390/resources9020015

Yore, L. D., \& Lerman, S. (2008). Metasyntheses of qualitative research studies in mathematics and science education. International Journal of Science and Mathematics Education, 6(2), 217-223. https:// doi.org/10.1007/s10763-008-9128-9

\section{http://www.ejmste.com}

